\title{
Endothelial progenitor cells to the rescue?
}

\author{
Leora B. Balsam, MD
}

\author{
From the Division of Cardiac Surgery, UMass Memorial Medical Center, Worcester, Mass. \\ Disclosures: Author has nothing to disclose with regard to commercial support. \\ Received for publication Aug 19, 2018; accepted for publication Aug 21, 2018; available ahead of print Sept 27, \\ 2018. \\ Address for reprints: Leora B. Balsam, MD, Division of Cardiac Surgery, UMass Memorial Medical Center, 55 \\ Lake Ave North, Worcester, MA 01655 (E-mail: leora.balsam@umassmemorial.org). \\ J Thorac Cardiovasc Surg 2019;157:667-8 \\ $0022-5223 / \$ 36.00$ \\ Copyright (C 2018 by The American Association for Thoracic Surgery \\ https://doi.org/10.1016/j.jtcvs.2018.08.041
}

Treatment for chronic thromboembolic pulmonary hypertension (CTEPH) consists of pulmonary endarterectomy, a surgical correction for chronic changes to pulmonary arterial structure and function. The right ventricular (RV) response to chronic pulmonary hypertension is initially compensatory, with development of RV hypertrophy to overcome pressure overload, yet over time, this response gives way to maladaptive RV dilatation and failure. One manifestation of the transition between the adaptive and maladaptive states is the development of $\mathrm{RV}$ ischemia related to a mismatch between RV capillary density and RV stroke work. ${ }^{1}$ In this issue of the Journal, Loisel and colleagues, ${ }^{2}$ in Paris, France, explore the potential therapeutic benefit of endothelial progenitor cell (EPC) therapy in restoring the balance between RV supply and demand in a large animal CTEPH model.

Treatments for chronic pulmonary hypertension typically target the primary pathology, focusing on reduction or resolution of obstruction or overload in the pulmonary vasculature. The World Health Organization has classified pulmonary hypertension into 5 groups based on its etiology; these include pulmonary arterial hypertension (PAH) (group 1), left heart disease (group 2), lung disease and chronic hypoxia (group 3), CTEPH (group 4), and blood and other disorders (group 5). Several animal models have been used to study these processes that are worth mentioning. ${ }^{3,4}$ First is the monocrotaline rodent model in which treatment with the chemical monocrotaline results in lung damage and PAH. Second is the chronic hypoxiaSU5416 model, in which combined chronic hypoxia and treatment with the vascular endothelial growth factor receptor antagonist SU5416 result in angio-obliterative lesions in the lungs and progressive pulmonary hypertension. Mercier and colleagues previously described their ovine CTEPH model, in which ligation of the left pulmonary artery and serial embolization of the right lower lobe pulmonary artery gradually leads to hemodynamic and morphologic changes similar to human CTEPH, including secondary RV remodeling.

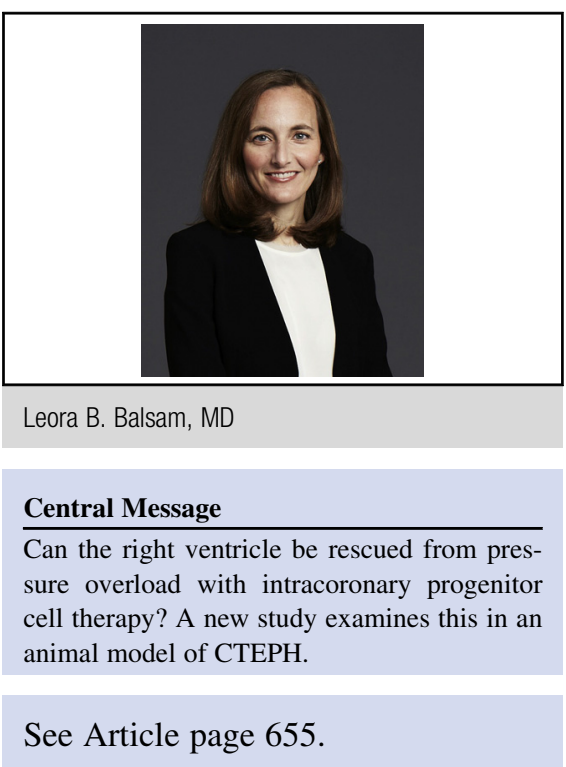

Stem cells have been used to target both the pulmonary vasculature and the right ventricle in animal models of pulmonary hypertension. Huang and colleagues ${ }^{5}$ found reduced pulmonary inflammation and improved RV hemodynamics in rats with monocrotaline-induced PAH treated with induced pluripotent stem cells. Zhou and colleagues ${ }^{6}$ also found reduction in monocrotaline-induced PAH (and beneficial effects on the right ventricle) in rats treated with EPCs engineered to express prostacyclin. Others found amelioration of monocrotaline-induced $\mathrm{PAH}$ in rats after combined treatment with a phosphodiesterase inhibitor (cilostazol or sildenafil) and EPCs. ${ }^{4,7}$

Loisel and colleagues ${ }^{2}$ deliver EPCs by right coronary artery injection in the CTEPH model and look for effects on RV structure and function over time. The authors hypothesize that RV-targeted therapy may be a useful adjunct even in the continued presence of pulmonary arterial obstruction. They propose that this benefit may occur secondary to paracrine effects of the EPCs or through direct cellular involvement in angiogenesis.

Coronary artery injection may be a clinically translatable method of stem cell delivery to the right ventricle, and Loisel and colleagues ${ }^{2}$ find that at early time points after treatment, labeled EPCs are found in the RV free wall. Different techniques have been described to improve RV engraftment of stem cells after intracoronary injection, including a stopreflow technique in which cell infusion occurs during temporary occlusion of the target coronary vessel. ${ }^{8,9}$ The downsides of all intracoronary delivery techniques is that 
they may be associated with myocardial ischemia, arrhythmias, and nonuniform engraftment of the delivered cells. For example, Wehman and colleagues ${ }^{9}$ found that stem cells delivered via the right coronary artery in a swine model localized primarily to the lateral RV free wall, with limited engraftment in the RV outflow tract, septum, or right atrium. Loisel and colleagues ${ }^{2}$ find a small increase in serum troponin after intracoronary EPC delivery, consistent with myocardial ischemia. They do not quantitatively measure early cell survival and engraftment, and at the late time points (4 weeks postinjection), none of the labeled EPCs were detectable in the RV. This of course brings to question the durability of this proposed therapy, because stable engraftment of the donor cells is not achieved.

At 4 weeks after EPC injection, the extent of pulmonary hypertension in the CTEPH animals was comparable to animals not receiving EPCs. Histologically, pulmonary arterial thickening was also similar in both groups. This confirmed that the intracoronary EPC treatment did not alter the primary disease process in the pulmonary vasculature. $\mathrm{RV}$ fractional area change was better in the CTEPH animals treated with EPCs compared with those without, as was the ventriculo-arterial coupling (ratio of RV elastance to pulmonary arterial elastance). However, other measures of RV structure and function were unchanged with cell treatment, including RV stroke work index, tricuspid annular plane systolic excursion, and RV free wall strain. Histologic analysis of the right ventricle showed a trend toward higher capillary density with cell treatment, less cardiomyocyte surface area (suggesting less hypertrophy), and increased expression of CD31, an endothelial marker. Overall, these data suggest that EPC treatment had a direct effect on RV structure that resulted in modest functional improvements. The fact that some RV functional parameters were improved and others were not suggests that overall the efficacy of the treatment was limited.

In a previous study, the authors noted an imbalance between capillary density and RV demand in the CTEPH model at a 20 -week timepoint. ${ }^{1}$ In the present study, ${ }^{2}$ the timeline is abbreviated, with analyses of RV structure and function at 10 weeks. At this time point, capillary density was high in both the cell-treated and untreated CTEPH groups (compared with sham), allowing for relatively compensated RV function in both groups. It would be useful to repeat these experiments at a later time point when RV maladaptive changes are more pronounced, because the benefit of EPC treatment may be greater then.

Certain human diseases are difficult to replicate in animal models, and Mercier and colleagues can be credited with the development of a complex CTEPH model. Understanding the pathobiology of CTEPH will likely open new therapeutic doors. It seems probable that greater impact will be achieved with therapies that target the primary pulmonary process (rather than the secondary RV effects), but combination therapies may yield a powerful synergy as well. Whether stem cell therapy will add lasting value in this therapeutic arena remains to be seen.

\section{References}

1. Noly PE, Haddad F, Arthur-Ataam J, Langer N, Doruller P, Loisel F, et al The importance of capillary density-stroke work mismatch for right ventricular adaptation to chronic pressure overload. J Thorac Cardiovasc Surg. 2017; 154:2070-9.

2. Loisel F, Provost B, Guihaire J, Boulate D, Arouche N, Amsallem M, et al. Autologous endothelial progenitor cell therapy improves right ventricular function in a model of chronic thromboembolic pulmonary hypertension. J Thorac Cardiovasc Surg. 2019;157:655-66.e7.

3. Suen CM, Zhai A, Lalu MM, Welsh C, Levac BM, Fergusson D, et al. Efficacy and safety of regenerative cell therapy for pulmonary arterial hypertension in animal models: a preclinical systematic review protocol. Syst Rev. 2016;5:89.

4. Yen CH, Tsai TH, Leu S, Chen YL, Chang LT, Chai HT, et al. Sildenafil improves long-term effect of endothelial progenitor cell-based treatment for monocrotalineinduced rat pulmonary arterial hypertension. Cytotherapy. 2013;15:209-23.

5. Huang WC, Ke MW, Cheng CC, Chiou SH, Shue-Ren W, Shu CW, et al. Therapeutic benefits of induced pluripotent stem cells in monocrotaline-induced pulmonary arterial hypertension. PLoS One. 2016;11:e0142476.

6. Zhou L, Chen Z, Vanderslice P, So SP, Ruan KH, Willerson JT, et al. Endothelial like progenitor cells engineered to produce prostacyclin rescue monocrotalineinduced pulmonary arterial hypertension and provide right ventricle benefits Circulation. 2013;128:982-94

7. Sun CK, Lee FY, Sheu JJ, Yuen CM, Chua S, Chung SY, et al. Early combined treatment with cilostazol and bone marrow-derived endothelial progenitor cells markedly attenuates pulmonary arterial hypertension in rats. J Pharmacol Exp Ther. 2009;330:718-26.

8. Eslam RB, Croce K, Mangione FM, Musmann R, Leopold JA, Mitchell RN, et al. Persistence and proliferation of human mesenchymal stromal cells in the right ventricular myocardium after intracoronary injection in a large animal model of pulmonary hypertension. Cytotherapy. 2017;19:668-79.

9. Wehman B, Siddiqui O, Jack G, Vesely M, Li T, Mishra R, et al. Intracoronary stem cell delivery to the right ventricle: a preclinical study. Semin Thoracic Surg. 2016;28:817-24. 